\title{
Educação Financeira: abordagem nos livros didáticos de Matemática para o Ensino Médio
}

\author{
Financial Education: approach in high school Mathematics textbooks
}

\author{
Vlademir Marim \\ Maxwell Gomes da Silva
}

\begin{abstract}
Resumo: Esta pesquisa tem como objetivo analisar as propostas significativas apresentadas nos livros didáticos de Matemática do Ensino Médio, no que diz respeito à Educação Financeira, que possam contribuir para a formação do professor de Matemática do Ensino Médio. Para atender a esse objetivo, optou-se pelo uso da metodologia comparada para justapor os dados concretos e abstrair as informações pertinentes ao estudo. Para a análise, considerou-se três eixos: livros didáticos, manual do professor e ensino e aprendizagem do docente. Conclui-se ser necessário olhar atentamente às possibilidades interdisciplinares para a Educação Financeira. Em geral, os livros abordam parte dessa formação, concentrando-se em cálculos, fórmulas e problemas envolvendo juros, prejuízos e empréstimos para o estudo da Matemática Financeira.
\end{abstract}

Palavras-chave: Educação Financeira. Metodologia comparada. Formação docente. Matemática.

\begin{abstract}
This research aims to analyze the significant proposals Mathematics textbooks, about financial education, which may contribute to the formation of the high school math teacher. To meet this objective, we chose to use the comparative methodology to juxtapose the concrete data and abstract the pertinent information to the study. For analysis, three axes were considered: textbooks, teacher's manual and teaching and learning of teacher. It is concluded that it is necessary to take an attentive look at the interdisciplinary possibilities with the work for the Financial Education. In general, the books approach part of this formation, concentrating on calculations, formulas and problems involving interest, losses and loans for the study of Financial Mathematics.
\end{abstract}

Keywords: Financial education. Comparative Methodology. Teacher formation. Mathematics.

\section{Contexto educacional no Brasil}

A Educação Básica no Brasil é constituída pelas relações dos processos formativos que se desenvolvem na vida familiar, na convivência humana, no trabalho e nas instituições de ensino e pesquisa em instituições públicas e privadas. Segundo a Lei de Diretrizes e Bases da Educação (LDB) n 9.394, de 1996, em seu Art. $1^{0}$, o sistema de ensino é obrigatório e gratuito para indivíduos de 4 a 17 anos de idade, estruturado em três etapas: Educação Infantil, Ensino Fundamental e
Vlademir Marim Doutor em Educação: Currículo pela Pontifícia Universidade Católica de São Paulo (PUC-SP). Professor da Universidade Federal de Uberlândia (UFU), campus Pontal. Minas Gerais, Brasil. (iD) orcid.org/0000-0002-4754-8802

$\triangle$ marim@ufu.br

Maxwell Gomes da Silva Mestrando em Matemática pela Universidade Federal de Uberlândia (UFU). Professor da Pontifícia Universidade Católica de Minas Gerais, (PUC Minas). Minas Gerais, Brasil. (iD) orcid.org/0000-0002-0724-8768 $\triangle$ maxwellgomessilva@gmail.com

Recebido em 17/08/2019 Aceito em 31/10/2019 Publicado em 19/03/2020 
Ensino Médio (BRASIL, 1996).

O último estágio da Educação Básica, chamado de Ensino Médio, possui duração de três anos, sendo direcionado para jovens com faixa etária de 15 a 17 anos de idade. Segundo a LDB, esta etapa de escolarização possui as seguintes finalidades:

a) a consolidação e o aprofundamento dos conhecimentos adquiridos no Ensino Fundamental, possibilitando o prosseguimento de estudos; b) a preparação básica para a cidadania e o trabalho, tomado este como princípio educativo, para continuar aprendendo, de modo a ser capaz de enfrentar novas condições de ocupação e aperfeiçoamento posteriores; c) o desenvolvimento do educando como pessoa humana, incluindo a formação ética e estética, o desenvolvimento da autonomia intelectual e do pensamento crítico; e d) a compreensão dos fundamentos científicos e tecnológicos presentes na sociedade contemporânea, relacionando a teoria com a prática. (BRASIL, 1996)

De acordo com a LDB, os anos finais do ciclo escolar devem consolidar o conhecimento acumulado ao longo da trajetória estudantil e preparar os alunos para se tornarem seres sociais ativos na sociedade, com capacidade produtiva, inovadora, de tal modo que a oferta de um bom Ensino Médio é crucial para pavimentar o caminho do jovem, seja para sua vida acadêmica ou profissional, possibilitando alcançar novas oportunidades.

Por outro lado, observa-se que no Brasil esta realidade é diferente de tais ideais, pois os dados analisados pelo Índice de Desenvolvimento da Educação Básica (IDEB), que é um indicador criado pelo governo federal para medir a qualidade do ensino nas escolas públicas do país, aponta que a Educação Básica no Brasil não atingiu avanços significativos.

Em especial, pode-se reiterar que no Ensino Médio a meta não foi alcançada nos três últimos anos avaliados, contudo, os índices desta etapa da Educação Básica permanecem estagnados. Fato este retratado no resultado divulgado no ano de 2017, apresentando que a média nacional alcançou apenas 3,8 pontos, frente à meta estabelecida de 4,7 pontos ${ }^{1}$, conforme ilustra o Quadro 1.

Esses dados evidenciam que os resultados da média nacional para o Ensino Fundamental e Ensino Médio não alcançaram as notas estabelecidas pelas metas do IDEB, determinadas pelo MEC, nos últimos três anos analisados: 2013, 2015 e 2017. Observando os dados do Ensino Médio, nota-se que de 2015 para 2017 oscilou apenas 0,1 ponto, e se comparados com os dados

\footnotetext{
1 Dados apresentados em matéria publicada no site do Ministério da Educação de 14 set. 2016, disponível em http://portal.mec.gov.br.
} 
dos anos de 2013 e 2015 o índice permaneceu o mesmo, 3,7 pontos. Logo, percebe-se que os resultados são insatisfatórios, tornando evidente que a formação dos estudantes nos últimos anos do ciclo da Educação Básica está longe do que se espera para o Brasil, em termos de desenvolvimento educacional.

Quadro 1: Resultados e metas do IDEB para a EB no Brasil para o ano de 2017

\begin{tabular}{|c|c|c|c|c|c|c|}
\hline \multicolumn{1}{|c|}{} & \multicolumn{2}{|c|}{$\begin{array}{c}\text { Anos Iniciais do } \\
\text { Ensino Fundamental }\end{array}$} & \multicolumn{2}{c|}{$\begin{array}{c}\text { Anos Finais do } \\
\text { Ensino Fundamental }\end{array}$} & \multicolumn{2}{c|}{ Ensino Médio } \\
\hline Ano & Meta & Resultado & Meta & Resultado & Meta & Resultado \\
\hline 2007 & 3,9 & 4,2 & 3,5 & 3,8 & 3,4 & 3,5 \\
\hline 2009 & 4,2 & 4,6 & 3,7 & 4,0 & 3,5 & 3,6 \\
\hline 2011 & 4,6 & 5,0 & 3,9 & 4,1 & 3,7 & 3,7 \\
\hline 2013 & 4,9 & 5,2 & 4,4 & 4,2 & 3,9 & 3,7 \\
\hline 2015 & 5,2 & 5,5 & 4,7 & 4,5 & 4,3 & 3,7 \\
\hline 2017 & 5,5 & 5,8 & 5,0 & 4,7 & 4,7 & 3,8 \\
\hline \multicolumn{2}{|c|}{ Fonte: Índice de Desenvolvimento da Educação Básica (BRASIL, 2018a) } \\
\hline
\end{tabular}

Ao analisar esse indicador, órgãos do governo e pesquisadores tentam explicar as causas do insucesso da educação no Ensino Médio. Para Marim et al. (2015), não existe um consenso entre os reais motivos desse fracasso, pois muitas explicações são dadas para esse baixo desempenho. Corroborando os autores, documentos institucionais consideram que a perda do desempenho escolar se dá pelo fato de o ensino brasileiro possuir uma estrutura curricular rígida, engessada e volumosa, em termos de disciplinas escolares.

O fato, porém, é que nos últimos anos o Brasil vem vivenciando uma crise econômica e política, ocasionando uma descontinuidade dos programas e propostas de ensino. Todo esse cenário de incertezas altera a forma de como os recursos são disponibilizados para os programas educacionais governamentais, bem como as propostas de melhorias do Índice de Desenvolvimento da Educação Básica (IDEB), já que a instabilidade econômica e política acarreta a troca constante dos representantes do Ministério da Educação, órgão responsável pela criação e manutenção das diretrizes educacionais do país.

Compreendendo esse contexto de instabilidade política, que age sobre a educação no 
país, enumera-se algumas denominações e variações nos projetos educacionais para o Ensino Médio, no espaço e tempo político do Brasil, abordado por Marim e Ferreira (2015, p. 131):

i) tivemos a antiga organização do Ensino Secundário em Ginasial e Colegial Clássico e Científico durante a Ditadura do Estado Novo (Decreto-lei nº. 4.244/42, Lei Orgânica do Ensino Secundário); ii) depois da redemocratização, passamos à igualdade de direitos da escola privada em relação à educação pública, na disputa de recursos, e à plena equivalência entre a educação profissional e técnica e o Ensino Médio (Lei de Diretrizes e Bases da Educação Nacional, LDB - Lei nº. 4.024/61); iii) a seguir, durante a Ditadura civil militar, veio a profissionalização obrigatória (Lei $n^{0} .5 .692 / 71$ ); iv) novamente, com a redemocratização, tivemos a preparação para prosseguir estudos superiores e a preparação para o trabalho (Lei de Diretrizes e Bases da Educação LDB, Lei n $\left.{ }^{0} .394 / 96\right)$; v) segue-se a separação entre o Ensino Médio e a educação profissional (sob as políticos neoliberais, pelo Decreto $n^{0}$. 208/97); vi) depois passamos à sua revogação, restaurando a integração entre o Ensino Médio e a educação profissional e mantendo o ensino concomitante e o subsequente. (Decreto $\mathrm{n}$. 5.154/04).

Do ponto de vista dos autores, nota-se que, ao longo desse espaço temporal, a educação no Brasil, em especial o Ensino Médio, passou por mudanças significativas a cada troca de governo, portanto, é possível evidenciar que esse cenário influencia diretamente o sistema de ensino, já que as alterações políticas e trocas de governantes trazem e carregam consigo as concepções e ideologias que correspondem aos seus anseios no período em que elas se situam.

Outra mudança ocorrida no ano de 2011, no contexto do Ensino Médio, foi marcada pela Lei № 12.513, de 26 de outubro de 2011, que instituiu o Programa Nacional de Acesso ao Ensino Técnico e Emprego (PRONATEC), com o objetivo de expandir, interiorizar e democratizar a oferta de cursos de educação profissional e tecnológica para alunos brasileiros.

Porém, com a mudança do cenário político no Brasil, ocasionado pelo impeachment da presidente Dilma Roussef, em 31 de agosto de 2016, o PRONATEC foi descontinuado pelo governo federal no ano seguinte.

Sob a ideologia do governo federal, a Educação Básica do Ensino Médio foi direcionada para uma nova proposta, pois o caminho traçado culminou em uma reformulação do Ensino Médio, destinado para a profissionalização e empregabilidade dos jovens, de tal modo que em 16 de fevereiro de 2017 foi promulgada a Lei n 13.415 , que incluiu a formação técnica e profissional ao Ensino Médio, tendo como foco complementar a LDB, a fim de relacionar a teoria com a prática dos estudantes. Desse modo, a formação profissional passa a compor a Educação Básica, neste caso, o Ensino Médio.

Essa mudança foi intitulada pelo MEC de Novo Ensino Médio (MEDIOTEC), constituindo- 
se uma ação que permite tornar menos rígida a grade curricular das escolas, possibilitando as instituições de ensino das redes públicas e privadas, no âmbito federal, oferecerem cursos de capacitação profissional.

Além dessas alterações, destaca-se a divulgação da Base Nacional Comum Curricular (BNCC) para o Ensino Médio, no ano de 2018, com a inclusão da Educação Financeira nos currículos de todo o Brasil, significando que esse tema passa a fazer parte de uma lista de assuntos que devem ser incorporados às propostas pedagógicas de estados e municípios (BRASIL, 2018b).

Mediante essa questão, é relevante destacar a importância do livro didático para os processos de ensino e de aprendizagem, pois ele é dado como um instrumento de suporte pedagógico, que permite contemplar as habilidades e competências dos conteúdos, bem como organizar o currículo escolar, planejar aulas, ser um material de consulta para os alunos e professores, e possibilitar o acesso e a construção do conhecimento.

Para Batista (2011), o livro didático é útil tanto ao professor quanto ao aluno, pois, por meio dele, os docentes poderão reforçar seus conhecimentos ou receber sugestões de como apresentá-los em sala de aula, atuando como instrumento mediador para a construção do conhecimento; já para os alunos, é uma maneira organizada e sistematizada de oferecer os conteúdos e matérias, possibilitando a ampliação do seu conhecimento.

O fato é que, ao longo dos anos, o sistema de ensino no Brasil passou por transformações significativas, pois ora inclui a formação profissional, ora a oferta é concomitante, ora é independente, ora é excluída da formação cidadã, de modo que a cada período político constatase que o livro didático deve acompanhar essas mudanças. Portanto, observa-se que este recurso pedagógico é influenciado por todas essas fases e momentos em que a educação é exposta.

Nesse cenário de mudanças na Educação Básica, emerge o problema de pesquisa: Como os livros didáticos de Matemática do Ensino Médio, em relação à Educação Financeira, podem contribuir na formação do professor para que ele propicie aos seus alunos sua inserção no mundo do trabalho de forma ativa, crítica, criativa e responsável, perante aos desafios da contemporaneidade?

Considerando esta questão, o objetivo desta pesquisa é analisar as propostas potencialmente significativas na formação docente, no que se refere à Educação Financeira, presentes nos livros didáticos de Matemática do Ensino Médio, para que os alunos atuem como 
cidadãos conscientes e ativos na sociedade, utilizando-se da metodologia comparada como instrumento de investigação.

Desejando alcançar o objetivo geral, torna-se necessário cumprir os seguintes objetivos específicos: a) identificar e selecionar três livros didáticos de Matemática do Ensino Médio com maior número de tiragem no PNLD de 2017; b) descrever e interpretar como os autores direcionam a formação do professor para o desenvolvimento de suas práticas docentes na educação, com interface na Educação Financeira; e c) fazer a comparação e justaposição das propostas das práticas docentes potencialmente significativas, nos livros didáticos, com interface à Educação Financeira.

Para realizar este estudo, optamos pela metodologia comparada, com foco no estudo das semelhanças e diferenças presentes nos livros didáticos selecionados segundo as delimitações previamente estabelecidas pelo problema.

Levando-se em conta que a escolha dessa metodologia de pesquisa fundamenta-se na possibilidade de analisar dados concretos, deduzindo elementos constantes nos materiais a serem estudados e que possibilitará a abstração das informações pertinentes para a análise deste trabalho, entende-se ser esta a melhor escolha para alcançar o objetivo proposto.

A fim de atender a esse propósito do trabalho, buscou-se teorias que pudessem contribuir para o desenvolvimento dos processos de ensino e de aprendizagem em relação à contemporaneidade. Para isso, identificou-se a Taxonomia de Bloom, que traz à luz 0 desenvolvimento cognitivo por meio do crescimento gradual de etapas, relacionadas com as tecnologias, ou seja, entende-se que essa teoria pode auxiliar na investigação e na resposta ao problema, já que se adapta ao contexto vivenciado pela sociedade.

\section{As concepções do ambiente de ensino e aprendizagem brasileiras}

Os processos de ensino e de aprendizagem se baseia na relação entre professores, alunos, recursos didáticos e o meio em que estão envolvidos, conforme ilustrado na Figura 1.

Com base nessa figura, observa-se que no processo da educação há uma relação entre dois ou mais agentes e o meio em que esse processo ocorre. Em sua composição, percebe-se a presença de três agentes, constituindo dois na figura do professor e do aluno, outro representado pelo meio em que ocorre e o último constituído por um ou vários recursos didáticos. 


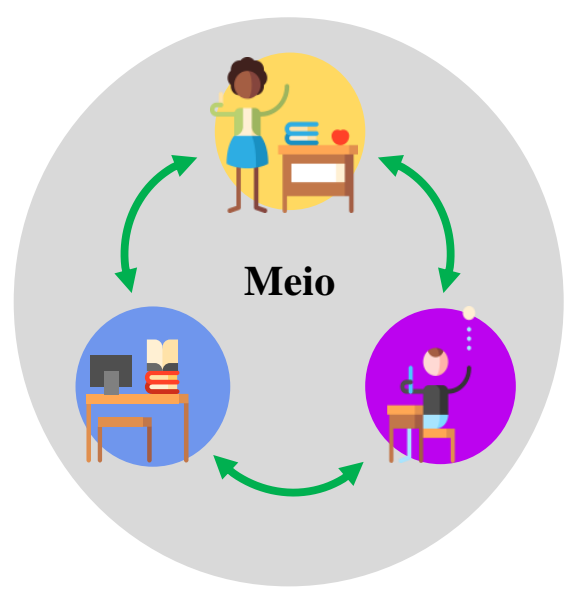

Figura 1: Relação entre os agentes no processo de ensino e aprendizagem (Elaboração dos Autores)

Entende-se como professor o responsável por conduzir ou compartilhar os processos de ensino e de aprendizagem com seus alunos; já o aluno, como o ser que busca conhecimento e meios para compartilhar os saberes; o meio como os espaços ou situações em que esse processo ocorre e, por último, os recursos didáticos, como os materiais, ferramentas, livros didáticos, computadores, calculadoras e outros, que permeiam esse processo, tomando-se como base as leis e regulamentações do Brasil.

Contribuindo com o processo educacional, é oportuno abordar como os objetivos de ensino e de aprendizagem serão decididos e definidos por essa analogia tetravalente, ou seja, a relação entre quatro elementos, com o viés de estruturar de forma consciente e oportunizar mudanças de pensamentos, ações e conduta.

Essa estruturação é resultado de um processo de planejamento relacionado à escolha do conteúdo, procedimentos, atividades, recursos disponíveis, estratégias, instrumentos de avaliação e a metodologia a ser adotada, por um determinado período, pelo educador.

Nesse contexto, um dos instrumentos que poderá facilitar essa estruturação nos processos de ensino e de aprendizagem é a taxonomia proposta por Bloom, que trata de uma ciência ou técnica com a perspectiva do domínio cognitivo sobre a aplicação do conhecimento e como ele é utilizado (BLOOM, 1956).

O termo taxonomia, segundo Bloom (1956), é concebido sob a ideia de classificar, estruturar, organizar e orientar um determinado processo. 0 emprego dessa sistemática apresenta vantagens, e para o cenário da educação pode-se destacar duas: 
de estratégias diferenciadas para facilitar, avaliar e estimular o desempenho dos alunos em diferentes níveis de aquisição de conhecimento; e ii) estimular os educadores a auxiliarem seus alunos, de forma estruturada e consciente, a adquirirem competências específicas a partir da percepção da necessidade de dominar habilidades mais simples (fatos) para, posteriormente, dominar as mais complexas (conceitos). (FERRAZ e BELHOT, 2010).

Para Bloom (1956), essa técnica é dividida em seis níveis: i) conhecimento, ii) compreensão, iii) aplicação, iv) análise, v) síntese e iv) avaliação, que atuam em uma dimensão, pertinente ao conhecimento.

Porém, como os processos de ensino evoluem com o passar do tempo, tendem a acompanhar as evoluções da sociedade e, segundo Anderson e Krathwohl (2001), é necessário incorporar novos conhecimentos e pensamentos, pois mudanças ocorreram na sociedade desde 1956 que influenciaram a maneira como pensamos e praticamos a educação.

Nessa visão, a Taxonomia de Bloom foi revisada passando a tratar duas dimensões: uma que diz respeito ao processo cognitivo e outra, ao conhecimento (KRATHAWOHL, 2002). Portanto, os níveis foram atualizados e correspondem aos seis níveis inicialmente apontados por Bloom, em 1956: i) lembrar: diz respeito ao conhecimento prévio de determinado assunto; ii) entender: trata da capacidade de compreender; iii) aplicar: como se dá a aplicação dos conceitos aprendidos; iv) analisar: competência em que a habilidade analítica é evidenciada; v) avaliar: refere-se ao pensamento crítico e habilidade de tomar decisões; e vi) criar: habilidade de sintetizar e transformar em algo novo (ANDERSON e KRATHAWOHL, 2001). Baseando-se nisso, elaborouse o Quadro 2.

\section{Quadro 2: Taxonomia de Bloom revisada}

\begin{tabular}{|c|c|c|c|c|}
\hline \multicolumn{2}{|c|}{ Taxonomia de Bloom Original } & & \multicolumn{2}{|r|}{ Taxonomia de Bloom Revisada } \\
\hline $\begin{array}{l}\text { Habilidade de lembrar } \\
\text { informações e conteúdos } \\
\text { previamente abordados como } \\
\text { fatos, datas, palavras, teorias, } \\
\text { métodos, classificações, lugares, } \\
\text { regras, critérios, procedimentos } \\
\text { e outros. }\end{array}$ & Conhecimento & $\rightarrow$ & Lembrar & $\begin{array}{c}\text { Reconhecer requer distinguir e } \\
\text { selecionar uma determinada } \\
\text { informação e reproduzir ou recordar } \\
\text { está mais relacionado à busca por } \\
\text { uma informação relevante } \\
\text { memorizada. }\end{array}$ \\
\hline $\begin{array}{l}\text { Habilidade de compreender e } \\
\text { dar significado ao conteúdo. } \\
\text { Essa habilidade pode ser } \\
\text { demonstrada por meio da } \\
\text { tradução do conteúdo } \\
\text { compreendido para uma nova }\end{array}$ & Compreensão & $\rightarrow$ & Entender & $\begin{array}{l}\text { Relacionado a estabelecer uma } \\
\text { conexão entre o novo e o } \\
\text { conhecimento previamente adquirido. } \\
\text { A informação é entendida quando o } \\
\text { aprendiz consegue reproduzi-la com } \\
\text { suas "próprias palavras". }\end{array}$ \\
\hline
\end{tabular}




\begin{tabular}{|c|c|c|c|c|}
\hline $\begin{array}{l}\text { forma (oral, escrita, diagramas } \\
\text { etc.) ou contexto. }\end{array}$ & & & & \\
\hline $\begin{array}{l}\text { Habilidade de usar informações, } \\
\text { métodos e conteúdos } \\
\text { aprendidos em novas situações } \\
\text { concretas. Isso pode incluir } \\
\text { aplicações de regras, métodos, } \\
\text { modelos, conceitos, princípios, } \\
\text { leis e teorias. }\end{array}$ & Aplicação & $\rightarrow$ & Aplicar & $\begin{array}{l}\text { Relacionado a executar ou usar um } \\
\text { procedimento numa situação } \\
\text { específica e pode também abordar a } \\
\text { aplicação de um conhecimento numa } \\
\text { situação nova. }\end{array}$ \\
\hline $\begin{array}{c}\text { Habilidade de subdividir o } \\
\text { conteúdo em partes menores } \\
\text { com a finalidade de entender a } \\
\text { estrutura final. Nesse ponto é } \\
\text { necessário não apenas ter } \\
\text { compreendido o conteúdo, mas } \\
\text { também a estrutura do objeto de } \\
\text { estudo. }\end{array}$ & Análise & $\rightarrow$ & Analisar & $\begin{array}{c}\text { Relacionado a dividir a informação } \\
\text { em partes relevantes e irrelevantes, } \\
\text { importantes e menos importantes e } \\
\text { entender a inter-relação existente } \\
\text { entre as partes. }\end{array}$ \\
\hline $\begin{array}{l}\text { Habilidade de agregar e juntar } \\
\text { partes com a finalidade de criar } \\
\text { um novo todo. Combinar partes } \\
\text { não organizadas para formar um } \\
\text { "todo". }\end{array}$ & Síntese & $y$ & Avaliar & $\begin{array}{c}\text { Relacionado a realizar julgamentos } \\
\text { baseados em critérios e padrões } \\
\text { qualitativos e quantitativos ou de } \\
\text { eficiência e eficácia. }\end{array}$ \\
\hline $\begin{array}{l}\text { Habilidade de julgar o valor do } \\
\text { material (proposta, pesquisa, } \\
\text { projeto) para um propósito } \\
\text { específico. Julgar o valor do } \\
\text { conhecimento. }\end{array}$ & Avaliação & $\pi$ & Criar & $\begin{array}{l}\text { Envolve o desenvolvimento de ideias } \\
\text { novas e originais, produtos e } \\
\text { métodos por meio da percepção da } \\
\text { interdisciplinaridade e da } \\
\text { interdependência de conceitos. }\end{array}$ \\
\hline
\end{tabular}

Fonte: Adaptado dos conceitos de Bloom (1956) e Anderson e Krathawohl (2001)

Na Taxonomia de Bloom Revisada, representada na segunda coluna do Quadro 2, encontram-se as alterações segundo Anderson e Krathawohl (2001), baseadas nas relações de cada uma das áreas aos processos de ensino e de aprendizagem. Observa-se que os autores abordam que o conhecimento se dá pelo desenvolvimento ou pelo processo em que o sujeito passa a construir o saber por si mesmo, ou seja, pode-se dizer é o ato ou método que envolve atenção, percepção, memória, raciocínio, juízo, imaginação, pensamento, linguagem e ação.

Entretanto, para identificar os níveis da taxonomia, os autores propõem uma lista de verbos, que podem estar presentes no material didático, nas falas dos docentes e dos alunos, nas ações, nos ambientes educacionais e outros. No Quadro 3 encontram-se alguns exemplos desses verbos. 
Quadro 3: Verbos referentes a cada nível da Taxonomia de Bloom revisada

\begin{tabular}{|c|c|}
\hline Níveis & Verbos \\
\hline Lembrar & $\begin{array}{l}\text { enumerar, definir, descrever, identificar, denominar, listar, nomear, combinar, realçar, } \\
\text { apontar, relembrar, recordar, relacionar, reproduzir, solucionar, declarar, distinguir, rotular, } \\
\text { memorizar, ordenar e conhecer. }\end{array}$ \\
\hline Entender & $\begin{array}{l}\text { alterar, construir, defender, definir, descrever, distinguir, discriminar, estimar, explicar, } \\
\text { ilustrar, inferir, reformular, prever, reescrever, resolver, resumir, classificar, discutir, } \\
\text { identificar, interpretar, reconhecer, redefinir, selecionar, situar e traduzir. }\end{array}$ \\
\hline Aplicar & $\begin{array}{l}\text { aplicar, alterar, programar, demonstrar, desenvolver, descobrir, dramatizar, empregar, } \\
\text { ilustrar, interpretar, manipular, modificar, organizar, preparar, produzir, relatar, resolver, } \\
\text { transferir, usar, construir, esboçar, escolher, escrever, operar e praticar. }\end{array}$ \\
\hline Analisar & $\begin{array}{l}\text { analisar, reduzir, classificar, comparar, determinar, deduzir, diagramar, distinguir, } \\
\text { diferenciar, identificar, ilustrar, apontar, relacionar, selecionar, separar, subdividir, calcular, } \\
\text { discriminar, examinar, experimentar, testar, esquematizar e questionar. }\end{array}$ \\
\hline Avaliar & $\begin{array}{l}\text { categorizar, combinar, compor, conceber, construir, criar, desenhar, elaborar, estabelecer, } \\
\text { explicar, formular, generalizar, inventar, modificar, organizar, originar, planejar, propor, } \\
\text { reorganizar, relacionar, revisar, reescrever, resumir, sistematizar, escrever, desenvolver, } \\
\text { estruturar, montar e projetar. }\end{array}$ \\
\hline Criar & $\begin{array}{l}\text { avaliar, averiguar, escolher, comparar, concluir, contrastar, criticar, decidir, defender, } \\
\text { discriminar, explicar, interpretar, justificar, relatar, resolver, resumir, apoiar, validar, } \\
\text { escrever, detectar, estimar, julgar e selecionar. }\end{array}$ \\
\hline
\end{tabular}

Fonte: Adaptado dos conceitos de Bloom (1956) e Anderson e Krathawohl (2001)

A lista apresentada no Quadro 3 possibilita reconhecer a presença ou não de determinado nível da Taxonomia de Bloom, no objeto em análise. Por exemplo, para verificar a presença do nível lembrar, basta observar se um dos verbos sugeridos fazem parte do contexto apresentado.

Após sua revisão, essa técnica passa a ser complementada e chamada de "0 desenvolvimento do conhecimento cognitivo na Taxonomia de Bloom" (KRATHAWOHL, 2002).

Outro ponto em questão dessa sistemática é que os níveis seguem uma hierarquia crescente, ou seja, ela é estruturada em níveis de complexidade crescente, do mais simples ao mais avançado, significando que, para desenvolver uma nova habilidade pertencente ao próximo nível, o aluno deve ter dominado e se apropriado das habilidades dos níveis anteriores (FERRAZ e BELHOT, 2010). Complementando o que foi dito, os autores destacam que

só após conhecer um determinado assunto alguém poderá compreendê-lo e aplicá-lo. Nesse sentido, a taxonomia proposta não é apenas um esquema para classificação, mas uma possibilidade de organização hierárquica dos processos cognitivos de acordo 
com níveis de complexidade e objetivos do desenvolvimento cognitivo desejado e planejado. (FERRAZ e BELHOT, 2010, p. 424)

Esses processos cognitivos de Bloom, além de representarem resultados de aprendizagem esperados, são cumulativos, o que caracteriza uma relação de dependência entre os níveis e a estrutura de como são organizados, em termos de complexidades dos processos mentais, para o aluno, como mostra a Figura 2.

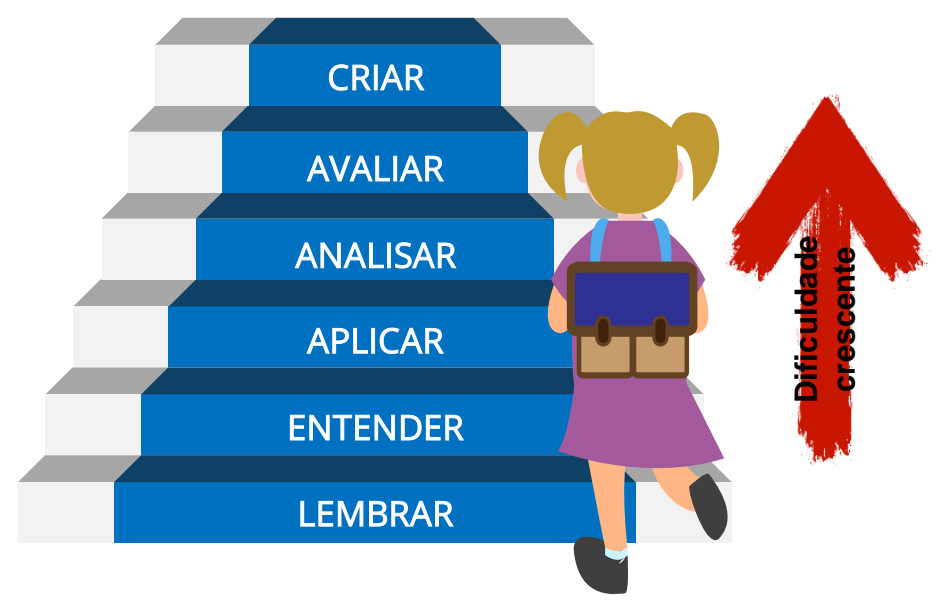

Figura 2: Escala de crescimento do domínio cognitivo (adaptada de Ferraz e Belhot, 2010).

Dito isso, observa-se que cabe ao professor traçar os objetivos e estruturar a sua disciplina, escolher o material didático, realizar o planejamento de aulas, optar por estratégias de avaliações, com olhar para o desenvolvimento e crescimento cognitivo de seus alunos.

Entretanto, todo desenvolvimento cognitivo deve seguir uma estrutura, para que os docentes possam aplicar e compartilhar o conhecimento adquirido (FERRAZ e BELHOT, 2010). Com base nessa premissa, a utilização de instrumentos que facilitem essa atividade é fundamental nesses processos de ensino e de aprendizagem. Nesse contexto, surge o papel da formação docente, com a função de formar profissionais do sistema de ensino e o emprego do livro didático como um recurso acessível e garantido por lei no Brasil.

Como se pode perceber, independentemente do método ou taxonomia a ser adotada pelo docente, a sistemática da educação não ocorre sem atuação desses agentes: aluno, professor, recurso didático e ambiente. À luz disso, iremos apresentar um breve contexto da história do livro didático e seu surgimento no ensino no Brasil.

A necessidade de as pessoas preservarem a sua história, seus feitos, conhecimentos, experiências e tudo o que para elas era importante, fez com que os homens, durante muitos 
séculos, procurassem várias formas e meios de deixar isso registrado.

Sobre isso, temos o ponto de vista de Paulino (2009) ao retratar que o registro das informações era realizado em pedras, tábuas de argila, papiro e pergaminho. Esses suportes consumiam espaço, alguns eram pesados, o número de cópias e a divulgação eram restritos, pois o transporte e o armazenamento eram limitados, e, assim, poucas pessoas tinham acesso a essas informações.

Toda essa dificuldade levou o homem a buscar outra forma de registro de seus conhecimentos, fatos e acontecimentos históricos. Assim, por volta do século II d.C., surge o códex, que era um modelo parecido com o nosso livro atual, formado por folhas escritas em ambos os lados, formado por várias páginas de papiro ou pele de animais costuradas, dobradas e amarradas ao longo da dobra, protegidos por uma capa (PAULINO, 2009)

Percebe-se que nessa época os livros eram todos manuscritos, o que restringia o número de edições de uma mesma obra, pois o esforço de reprodução era grande. Por outro lado, mesmo com todas as vantagens apresentadas pelo códex, o acesso não era fácil e limitado aos sacerdotes, monarcas e a alta sociedade da época.

Na década de 1450, um alemão chamado Gutemberg inventou a prensa, revolucionando a história da produção de livros, possibilitando a reprodução de obras com rapidez, automatizando o processo de formalização, pois eles passaram a ser impressos e não mais escritos à mão.

Em meio a esse caminho de mudanças, o livro ganhou os espaços escolares, como um instrumento de apoio na educação de crianças, jovens e adultos. Alguns autores sugerem que 0 livro didático (LD) apareceu no século XIX, figurando como um adicional à Bíblia, que até então era 0 único livro aceito pelas comunidades e usado nas escolas (OLIVEIRA, GUIMARÃES e BOMÉNY, 1984).

O autor destaca que o LD, naquela época, passou a assumir um papel importante na aprendizagem, na política educacional e, sobretudo, eram escritos para os alunos da elite (burguesia), ou seja, pessoas que compunham a classe de indivíduos com acúmulo de riquezas, cargos políticos e indivíduos vinculados à igreja, com o intuito da abordar os ensinamentos não disponíveis nos livros sagrados, como o emprego de cálculos, história da humanidade, evolução dos seres vivos, ortografia, gramática e diversos outros saberes (OLIVEIRA, GUIMARÃES e BOMÉNY, 1984). 
No Brasil, as primeiras ideias sobre o livro didático surgiram em 1929, com a configuração do Instituto Nacional do Livro (INL), órgão do governo responsável pela legitimação desse material e auxiliar em sua produção. No entanto, somente em 1934, no governo do presidente Getúlio Vargas, esse órgão começou a elaborar um dicionário nacional, uma enciclopédia para a educação e aumentar o número de bibliotecas públicas.

Várias formas foram experimentadas por um período de 67 anos - 1929 a 1996 - para que o livro didático chegasse às escolas e às salas de aulas, mas somente em 1997, com a constituição do Programa Nacional do Livro Didático (PNLD), é que se iniciou a produção contínua e distribuição massiva desses recursos didáticos para as escolas.

Nesse processo, destacamos que a escolha do LD, nos sistemas educacionais das escolas públicas no Brasil, é legitimada pelo PNLD, sendo este um programa de seleção e avaliação de obras didáticas, pedagógicas e literárias, e outros materiais de apoio à prática educativa, que são disponibilizados gratuitamente para as instituições públicas da educação básica, conveniadas com o poder público.

Como podemos notar, o PNLD é uma política pública que funciona como um mecanismo de regulamentação e permite que o governo avalie os livros didáticos e outros materiais educativos. Diante disso, esses materiais passam por critérios gerais de avaliação, os quais contextualizam se as propostas didático-pedagógicas estão em consonância com a legislação vigente, se os conteúdos das obras atendem aos requisitos das Diretrizes Curriculares Nacionais (DCN), se contribuem para a formação do professor, dentre outros.

Depois que essas obras são avaliadas, as informações são publicadas nos Guias de Livros Didáticos, seja por meio físico ou digital, que ficam disponíveis no site do Fundo Nacional do Desenvolvimento da Educação (FNDE), caracterizado como uma autarquia federal vinculada ao MEC, responsável pela realização da maioria das ações e programas relacionados à educação de nosso país.

A escola realiza a seleção dos livros somente pelo portal da internet do FNDE. Nele, constam todas as informações do PNLD: a apresentação, dados históricos, funcionamento, dados estatísticos, guias para a escolha, apoio à gestão, manuais, informes do PNLD, editais para convocação de editores e termo de adesão.

Tendo em vista o exposto, sabe-se que o livro didático é um dos materiais mais disseminados no ambiente escolar no Brasil. Pode ser compreendido como um material impresso, 
estruturado em capítulos ou seções, com o propósito de dar subsídio aos processos de ensino e de aprendizagem, bem como a formação do docente, ou seja, um recurso indispensável para a educação (MARIM e SOUZA, 2015).

Observa-se que o papel do LD é de dupla utilização, mas com um sentido único como agente do ensino e da aprendizagem, já que possui funções similares para ambos e atende à especificidade de facilitar o processo educacional, portanto, evidencia-se as seguintes características comuns: i) um recurso que permite nortear as aulas; ii) cumprir o currículo das disciplinas; iii) atender às especificidades das Diretrizes Curriculares Nacionais (DCN); e iv) seguir as regulamentações e leis regidas pelo MEC.

Sobre tudo isso, ressalta-se que o livro didático faz parte da prática escolar, articulado em diferentes enfoques educacionais e métodos de ensino, por constituir uma solução de trabalho para o professor, por auxiliar o docente a efetuar uma seleção de matéria a ser aplicada e a estabelecer certo tipo de abordagem e tratamento, possibilitando a proposição de um trajeto próprio para a construção do saber, com seus alunos.

Outro aspecto relevante é que as políticas públicas do PNLD garantem sua abrangência em todo território nacional. Como ponto de observação, tomamos os dados do censo demográfico e estima-se que a população brasileira é de aproximadamente 211 milhões de pessoas (BRASIL, 2020) e que no PNLD de 2017 foram distribuídos em torno de 145 milhões livros didáticos (BRASIL, 2017) para a educação básica das escolas públicas, ou seja, a quantidade de exemplares distribuídos equivale a quase $70 \%$ da população. Isto mostra 0 quanto ele está presente no sistema de ensino do país.

Por mais que seja discutida a importância de diversificar os mecanismos didáticos de ensino e aprendizagem, o livro pode ser considerado como o principal protagonista para a construção do conhecimento no espaço escolar. Nesse sentido, constata-se que esse recurso didático condiz com a realidade do ensino e pode-se elucidar que ele é uma importante ferramenta que oferece apoio aos processos educativos.

\section{Metodologia Comparada}

A pesquisa fundamenta-se na metodologia comparada. Segundo Lourenço Filho (2004), consiste em investigar coisas ou fatos e explicá-los segundo suas semelhanças e diferenças, 
permitindo uma análise de dados concretos por médio da dedução de semelhanças e divergências de elementos constantes, abstratos e gerais, para delinear o que é comum nesta investigação. Contribuindo com esta definição, Prodanov e Freitas (2013) afirmam que este método procede pela investigação de indivíduos, classes, fenômenos ou fatos, com vistas a ressaltar as diferenças e as similaridades entre eles.

O emprego do método comparativo está centrado em estudar as semelhanças e diferenças nos dados coletados, o que permite ao pesquisador analisar os resultados e obter as informações necessárias para responder ao objeto de seu estudo, de tal modo que a aplicação da metodologia comparada se dá por meio da realização de quatro fases, segundo Caballero et al. (2016): (a) descritiva: é o momento em que o pesquisador apresenta os indicadores, de forma descritiva e clara para permitir obter os dados iniciais da comparação; (b) interpretativa: em que há o contexto dos dados do estudo, para que se possa compreender e explicar as informações no período em que elas ocorrem; é o momento em que se valoriza e respeita os elementos da pesquisa; (c) justaposição: é a etapa em que o pesquisador estabelece as relações daquilo que se quer comparar; e (d) comparação: é o momento mais rico do projeto de pesquisa, pois nesta etapa tudo é sintetizado, sistematizado, organizado e são defendidas as diferenças e semelhanças encontradas no objeto de estudo.

Levando-se em conta que a escolha desta metodologia de pesquisa fundamenta-se na possibilidade de permitir analisar dados concretos, deduzindo elementos constantes nos materiais a serem estudados e que possibilitarão a abstração das informações pertinentes para o estudo deste trabalho, entendemos ser a melhor escolha para conseguirmos alcançar o objetivo proposto. Por outro lado, recomenda-se a utilização de dois momentos do método:

\footnotetext{
En primer lugar el diseño de la investigación: quedaría definido con las tres primeras fases a saber: selección y definición del problema, formulación de hipótesis e presupuestos de partida, y elección de la unidad de análisis. En segundo lugar, y una vez definido el diseño de investigación, pasamos al desarrollo de la investigación. Éste quedaría recogido en las cuatro fases que constituyen el núcleo de la investigación: fase descriptiva, fase interpretativa, fase de yuxtaposición y fase comparativa. (CABALLERO et al., 2016, p. 48)
}

Nesta citação, podemos observar que a metodologia comparada é separada em duas fases, as quais direcionam o pesquisador na condução de seus estudos e que podem facilitar 0 desenvolvimento de sua pesquisa. Portanto, consideramos oportuno que, antes de realizar as quatro etapas desse procedimento de pesquisa, se concretize o desenho metodológico, 
apresentando o esboço da investigação, definindo primeiramente o problema da investigação e o seu ponto de partida.

O desenho metodológico comparado é o primeiro momento da investigação. Devemos partir da formulação do problema, a elaboração dos pressupostos de partida e, por último, a seleção das unidades de análise (CABALLERO et al., 2016). Optamos por adotar essa divisão em dois passos, pois é relevante, em um primeiro momento da pesquisa, realizar o planejamento dos caminhos da investigação do problema e aplicar a metodologia comparada, ou seja, utilizar-se das quatro etapas desse processo.

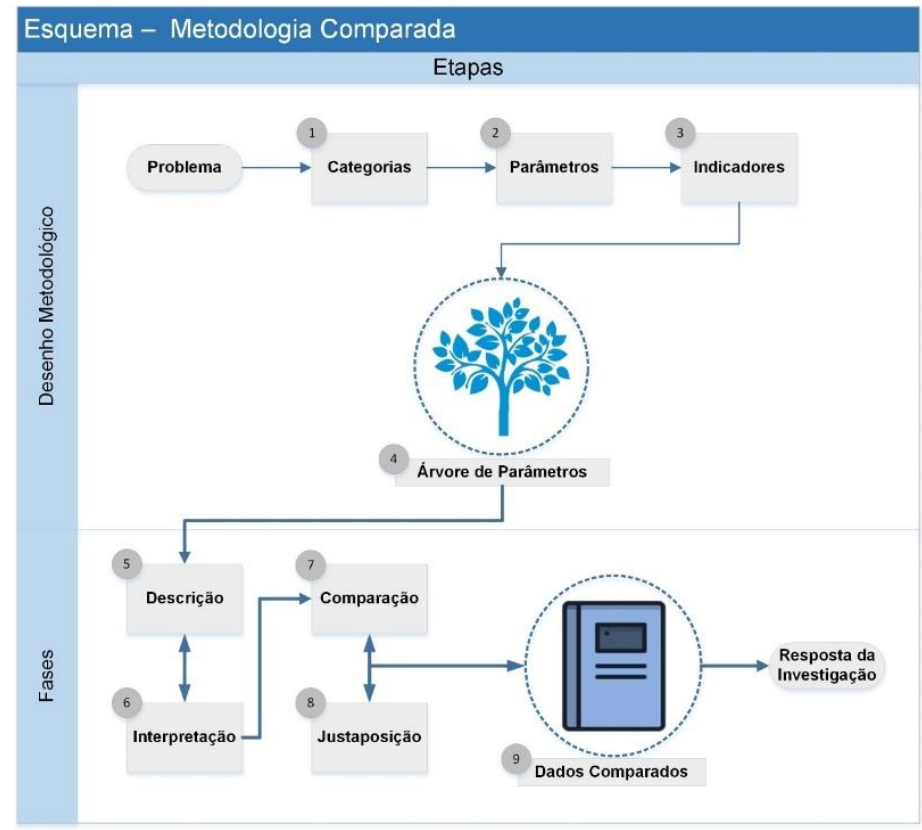

Figura 3: Esquema seguido na pesquisa (Elaboração dos Autores)

À luz disso, torna-se necessário estruturar o desenho metodológico a ser seguido e, em seguida, traçar a árvore de categorias, parâmetros e indicadores. Para facilitar a compreensão do que foi exposto a respeito da metodologia comparada e da etapa do desenho a ser seguido, foi elaborado um esquema, representado pela Figura 3. A intenção é de que o leitor possa compreender a trajetória a ser seguida.

Entendemos que o problema é o marco inicial de um projeto de pesquisa. A partir dele, decorrem os demais elementos fundamentais, como: indicadores, objetivos, metodologia, referências e outros (PESCUMA e CASTILHO, 2013). Assim, definimos o problema como o ponto crucial da investigação, ou seja, o que se deseja buscar como respostas.

Logo em seguida, apresenta-se a árvore de parâmetros, e, para compreendermos, 
podemos defini-la como uma forma de estruturar as questões norteadoras, para tentar responder ao problema da pesquisa. Ela é composta por três partes: (a) categorias: agrupamentos de parâmetros de natureza semelhante; (b) parâmetros: agrupamentos de indicadores de natureza parecida e (c) indicadores: unidade de comparação (CABALLERO et al., 2016).

A partir disso, realiza-se as quatro fases da metodologia comparada e, como podemos notar, optou-se por desenvolver as fases de descrição e interpretação concomitantemente, bem como a realização simultânea da comparação e justaposição. Essas fases podem ocorrer da maneira disposta, pois são complementares, subsidiam a coleta de informações e intepretação necessárias para nosso parecer final.

Em sentido amplo, os motivos que nos levaram à escolha do emprego da metodologia comparada são fundamentados pelo suporte que permitirá buscar esclarecer e responder ao problema, bem como possibilitar aprofundar as características, semelhanças e diferenças desses livros didáticos, frente à análise das propostas de ensino e de aprendizagem da Educação Financeira para o Ensino Médio.

\section{Seleção dos dados e a organização das categorias, parâmetros e indicadores}

Nesta pesquisa, optou-se por identificar e selecionar três coleções de livros de Matemática do Ensino Médio (EM), com maior número de tiragem no PNLD de 2017, ou seja, as três coleções mais adotadas pelas escolas sob domínio público. Todavia, tornou-se necessário pesquisar como essas quantidades estão disponíveis para consulta pública, já que toda escola pública deve escolher o livro por meio de solicitações on-line no portal da internet do FNDE.

Após consultas e buscas pela internet, encontramos as informações desejadas na seção Dados Estatísticos do Programa do Livro, acessando o site do FNDE. Nessa página, foi possível obter um arquivo digital contendo a lista, quantidade e valores dos livros escolhidos pelas escolas no Brasil, com o título: "PNLD 2017 - Dados estatísticos por estado - Ensino Fundamental e Médio"2.

Esse documento traz informações de todos os livros adquiridos pelo governo para as escolas sob seu domínio, no ano de 2017, desde os anos iniciais do Ensino Fundamental até o Ensino Médio. Em seguida, estratificou-se a quantidade de livros didáticos destinados ao EM e foi

\footnotetext{
2 Disponivel em http://www.fnde.gov.br.
} 
construída a Tabela 1.

Tabela 1: Tiragem de livros didáticos do EM em 2017

\begin{tabular}{c|c|r|c|}
\hline Ordem & Editora & Quantidade & \multicolumn{1}{c|}{$\%$} \\
\hline $1^{0}$ & A & 5.856 .206 & $22,1 \%$ \\
\hline $2^{\circ}$ & B & 4.321 .259 & $16,3 \%$ \\
\hline $3^{\circ}$ & C & 3.456 .879 & $13,0 \%$ \\
\hline $4^{\circ}$ & D & 3.403 .341 & $12,8 \%$ \\
\hline $5^{\circ}$ & E & 3.066 .882 & $11,6 \%$ \\
\hline $6^{\circ}$ & F & 1.770 .181 & $6,7 \%$ \\
\hline $7^{\circ}$ & G & 1.527 .297 & $5,8 \%$ \\
\hline $8^{\circ}$ & H & 886.585 & $3,3 \%$ \\
\hline $9^{\circ}$ & I & 615.122 & $2,3 \%$ \\
\hline $10^{\circ}$ & J & 499.645 & $1,9 \%$ \\
\hline $11^{\circ}$ & K & 436.666 & $1,6 \%$ \\
\hline $12^{\circ}$ & L & 244.833 & $0,9 \%$ \\
\hline $13^{\circ}$ & M & 182.454 & $0,7 \%$ \\
\hline $14^{\circ}$ & N & 101.667 & $0,4 \%$ \\
\hline $15^{\circ}$ & O & 94.455 & $0,4 \%$ \\
\hline $16^{\circ}$ & P & 18.333 & $0,1 \%$ \\
\hline $17^{\circ}$ & Q & 14.137 & $0,1 \%$ \\
\hline & Total: 26.495 .942 & \\
\hline & F & & \\
\hline
\end{tabular}

Fonte: Elaboração dos Autores

Logo em seguida, ordenou-se a coluna da quantidade em ordem decrescente, ou seja, do maior para o menor, a fim de identificar as três coleções que obtiveram maior número de exemplares selecionados pelas escolas e professores. O nome comercial das editoras foi substituído por letras do alfabeto, em ordem crescente, a fim de preservar a sua identidade.

Como se observa no PNLD de 2017, várias editoras foram listadas na Tabela 1 e para 
atender ao objetivo específico estabelecido, optou-se pela escolha das editoras A, B e D.

Para complementar a justificativa da escolha das três editoras, foi elaborado o Gráfico 2. Nele, constam as informações da Tabela 1, em termos percentuais, e foi possível observar que a editora $\mathrm{D}$ e $\mathrm{C}$ possuem valores que se equiparam graficamente, ou seja, a visão é praticamente similar.

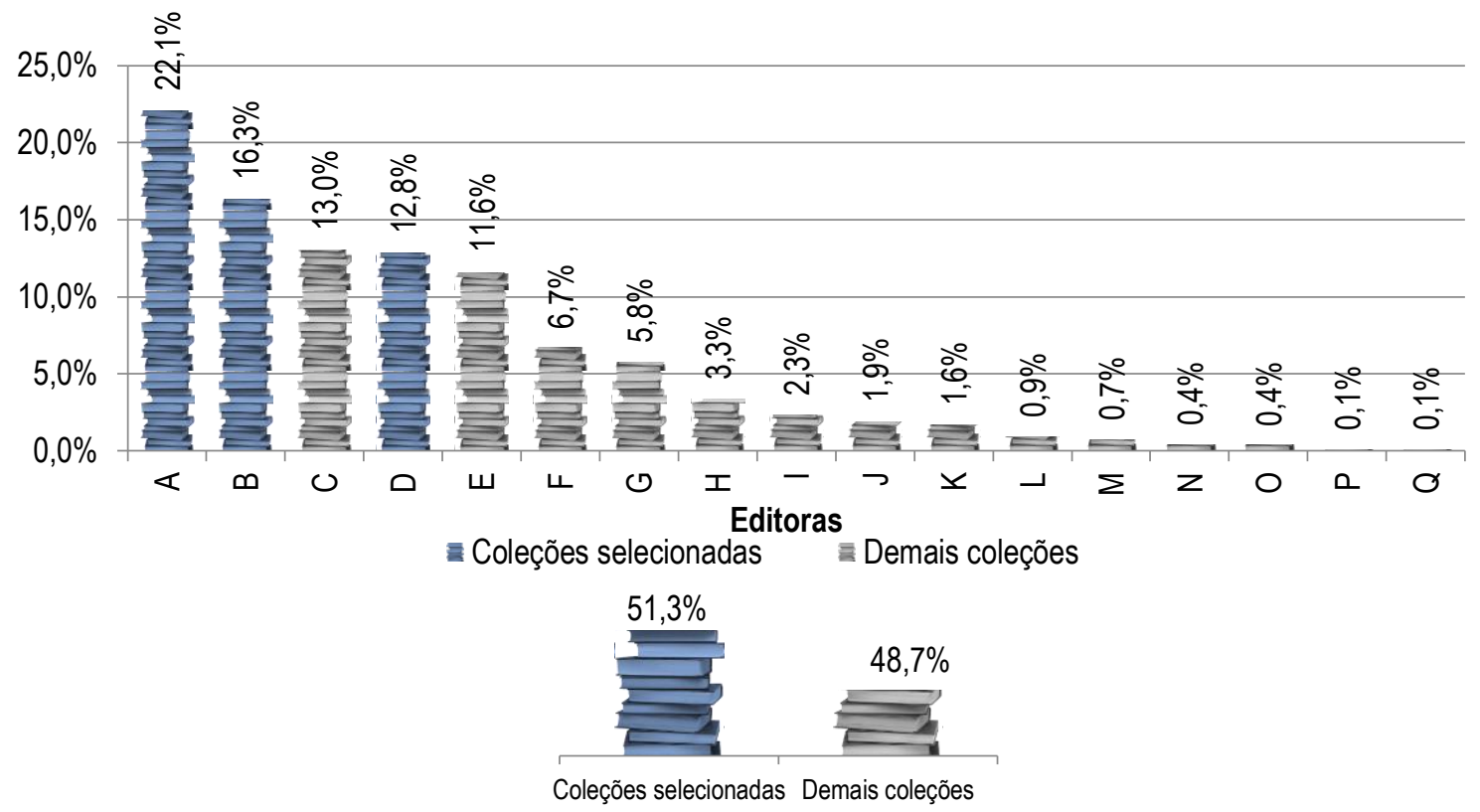

Gráfico 1: Consolidação dos dados da Tabela 1 em percentuais (Elaboração dos Autores)

Ao todo, em 2017, foram distribuídos para as escolas públicas 26.495 .942 (vinte e seis milhões, quatrocentos e noventa e cinco mil, novecentos e quarenta e dois) livros didáticos de Matemática para o EM no país. Frente a esse número, podemos dizer que as três editoras selecionadas para esta pesquisa representam aproximadamente $51,3 \%$ (Gráfico 1) do total de livros didáticos distribuídos nas escolas públicas, consolidando um total de 13.580 .806 (treze milhões, quinhentos e oitenta mil, oitocentos e seis) livros.

Logo em seguida, inicia-se a coleta de dados, por meio das fases de descrição e interpretação da metodologia comparada. Essas fases possibilitaram a extração de informações e estruturação da árvore de categorias, parâmetros e indicadores. Esta é uma forma de organizar as questões norteadoras do estudo e é composta por três partes: a) categorias: agrupamentos de parâmetros de natureza semelhantes; b) parâmetros: agrupamentos de indicadores de natureza parecida; e c) indicadores: unidade de comparação (CABALLERO et al., 2016). Dado isso, elaborou-se o Quadro 4. 
Quadro 4: Árvore de categorias, parâmetros e indicadores

\begin{tabular}{|c|c|c|}
\hline Categorias & Parâmetros & Indicadores \\
\hline \multirow{13}{*}{ 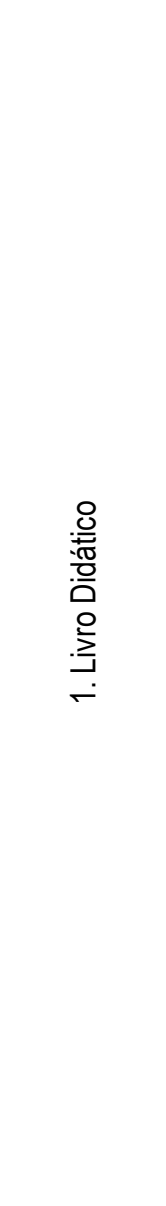 } & \multirow{3}{*}{$\begin{array}{l}\text { 1.1. Estrutura } \\
\text { física do livro }\end{array}$} & 1.1.1. Análise da estrutura física dos livros. \\
\hline & & 1.1.2. Relação das ilustrações com o conteúdo. \\
\hline & & 1.1.3. Contribuição das vinhetas para processo conceitualização do conteúdo. \\
\hline & \multirow{4}{*}{$\begin{array}{l}\text { 1.2. Organização } \\
\text { do capítulo da } \\
\text { Educação } \\
\text { Financeira }\end{array}$} & 1.2.1. Identificação do(s) volume(s) que aborda(m) a Educação Financeira. \\
\hline & & 1.2.2. Organização do capítulo. \\
\hline & & 1.2.3. Disposição das atividades ao longo do capítulo. \\
\hline & & 1.2.4. Abordagem das avaliações. \\
\hline & \multirow{4}{*}{$\begin{array}{l}\text { 1.3. Abordagem } \\
\text { metodológica da } \\
\text { Educação } \\
\text { Financeira }\end{array}$} & $\begin{array}{l}\text { 1.3.1. Desenvolvimento das habilidades básicas para o ensino e aprendizagem da } \\
\text { Educação Financeira. }\end{array}$ \\
\hline & & 1.3.2. Trabalho em grupo proposto pelas atividades. \\
\hline & & 1.3.3. As atividades possibilitam despertar o interesse dos alunos. \\
\hline & & $\begin{array}{l}\text { 1.3.4. Sugestões de uso de recursos didáticos, tais como: computadores, } \\
\text { calculadoras, aplicativos etc. }\end{array}$ \\
\hline & \multirow{2}{*}{$\begin{array}{l}\text { 1.4. Abordagem } \\
\text { científica da } \\
\text { Educação } \\
\text { Financeira }\end{array}$} & $\begin{array}{l}\text { 1.4.1. Relevância metodológica para alfabetização do aluno, no contexto da } \\
\text { Educação Financeira. }\end{array}$ \\
\hline & & $\begin{array}{l}\text { 1.4.2. Incentivo aos alunos a registrarem possíveis descobertas e procedimentos } \\
\text { da construção dos saberes. }\end{array}$ \\
\hline \multirow{6}{*}{ 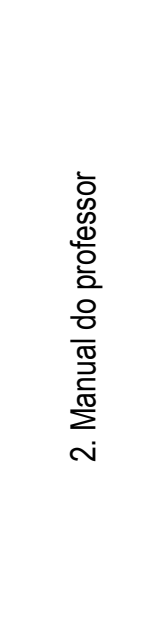 } & \multirow{3}{*}{$\begin{array}{l}\text { 2.1. Caminhos } \\
\text { para a formação } \\
\text { docente }\end{array}$} & 2.1.1. Planejamento de aulas. \\
\hline & & $\begin{array}{l}\text { 2.1.2. Abordagem de discussões e reflexões com o docente acerca do conteúdo e } \\
\text { habilidades propostas. }\end{array}$ \\
\hline & & 2.1.3. Autonomia do docente no desenvolvimento das atividades. \\
\hline & & $\begin{array}{l}\text { 2.2.1. Contribuições das orientações no manual do professor para a formação } \\
\text { docente. }\end{array}$ \\
\hline & $\begin{array}{l}\text { L.L. Formaçao } \\
\text { docente da } \\
\text { Educação }\end{array}$ & $\begin{array}{l}\text { 2.2.2. Presença de instruções, textos complementares, uso de equipamentos } \\
\text { tecnologias e outros recursos pedagógicos voltados para o docente. }\end{array}$ \\
\hline & & $\begin{array}{l}\text { 2.2.3. Reflexões dos conhecimentos relacionados à área da Educação Financeira, } \\
\text { ao professor. }\end{array}$ \\
\hline 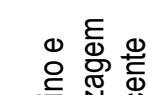 & 3.1. Lembrar & $\begin{array}{l}\text { 3.1.1. Estabelecimento de um primeiro contato com o conteúdo e possibilitar ao } \\
\text { docente relembrar/citar definições e outros conceitos de base. }\end{array}$ \\
\hline $\begin{array}{l}\text { யे 등 } \\
\text { ம் 응 응 }\end{array}$ & 3.2. Entender & $\begin{array}{l}\text { 3.2.1. Permite que o docente interprete os termos e conceitos propostos, tornando- } \\
\text { o capaz de traduzir a mesma por ideia em palavras próprias. }\end{array}$ \\
\hline
\end{tabular}




\begin{tabular}{|c|c|}
\hline 3.3. Aplicar & $\begin{array}{l}\text { 3.3.1. Permite que o docente realize aplicações em situações que simulem o dia a } \\
\text { dia, aproximando o ensino das práticas sociais. }\end{array}$ \\
\hline 3.4. Analisar & 3.4.1. Permite ao docente explicar os conceitos e estabelecer relações entre eles. \\
\hline 3.5. Avaliar & $\begin{array}{l}\text { 3.5.1. Proporciona situações para estimular a capacidade crítica e comparativa do } \\
\text { docente, considerando os conhecimentos prévios. }\end{array}$ \\
\hline 3.6. Criar & $\begin{array}{l}\text { 3.6.1. Relaciona as informações de fontes variadas, para que o docente construa } \\
\text { um novo produto. }\end{array}$ \\
\hline
\end{tabular}

Fonte: Elaboração dos Autores

Acerca dos materiais selecionados por essa pesquisa, buscou-se observar as questões do Quadro 4, a fim de responder a este estudo. Como se pode notar, foram analisadas as questões do livro do aluno, do manual do professor e do ensino e aprendizagem do docente.

\section{Justaposição e comparação}

Inicialmente, buscou-se identificar a presença da Educação Financeira nos três livros selecionados, porém, especificamente sobre esse tema não encontramos elementos que destacassem essa área do conhecimento. Mas, identifica-se o capítulo voltado para Matemática Financeira, que são conhecimentos e técnicas matemáticas para compreender e aplicar no contexto da Educação Financeira.

Nas duas primeiras categorias, buscou-se comparar a estrutura física dos livros, a quantidade de páginas, a natureza dos exercícios, como o livro possibilita o desenvolvimento das habilidades básicas para o ensino e a aprendizagem, os caminhos traçados para contribuir na formação docente, entre outros, conforme estabelecido na árvore de categorias, parâmetros e indicadores.

Esse primeiro momento é a base para a análise da última categoria, pois permite conhecer o material, descrever e interpretar os objetivos desenhados pelos autores para propor o conteúdo da Educação Financeira, mas, como apontado anteriormente, o viés deste tema é voltado para a Matemática Financeira.

Após esta análise e o reconhecimento dos materiais, seguiu-se para a última categoria de ensino e aprendizagem do docente, que tem como base os conceitos da Taxonomia de Bloom, que trata de uma ciência ou técnica com a perspectiva do domínio cognitivo sobre a aplicação do conhecimento e como ele é utilizado (BLOOM, 1956). Essa técnica é dividida em seis níveis, 
detalhados no Quadro 5.

Quadro 5: Parâmetros e domínios cognitivos de Bloom, revisado

\begin{tabular}{|c|c|}
\hline Parâmetro & Observações no Manual do Professor \\
\hline Lembrar & $\begin{array}{l}\text { Buscou-se observar os processos que requerem que o docente reproduza com exatidão } \\
\text { uma informação que lhe tenha sido dada, seja ela uma data, um relato, um procedimento, } \\
\text { uma fórmula, ou uma teoria. }\end{array}$ \\
\hline Entender & $\begin{array}{l}\text { Relativo à observação dos elementos que remetem ao ato de elaboração (modificação) de } \\
\text { um dado ou informação original, pelo docente. A elaboração ainda não será de } \\
\text { complexidade elevada, o docente deverá ser capaz de usar uma informação original e } \\
\text { ampliá-la, reduzi-la, representá-la de outra forma ou prever consequências resultantes da } \\
\text { informação original. }\end{array}$ \\
\hline Aplicar & $\begin{array}{l}\text { Baseada na reunião de processos em que o professor transporta uma informação genérica } \\
\text { para uma situação nova e específica. }\end{array}$ \\
\hline Analisar & $\begin{array}{l}\text { Buscou-se identificar os processos e características que possibilitassem aos docentes } \\
\text { separar uma informação em elementos componentes e estabelecer relações entre eles. } \\
\text { Entre outras coisas, pressupôs identificar aspectos centrais de uma proposição, verificar a } \\
\text { sua validade, constatar possíveis incongruências lógicas. }\end{array}$ \\
\hline Avaliar & $\begin{array}{l}\text { Procurou-se observar a apresentação dos processos cognitivos mais complexos. } \\
\text { Basicamente, visualizar a consistência do confronto de um dado, de uma informação, de } \\
\text { uma teoria, de um produto etc., com um critério ou conjunto de critérios, que podem ser } \\
\text { internos ao próprio objeto da avaliação ou externos a ele, pelo docente. }\end{array}$ \\
\hline Criar & $\begin{array}{l}\text { Buscou-se a representação das informações nas quais o professor possa reunir os } \\
\text { elementos de conhecimento para compor algo novo que terá, necessariamente, traços } \\
\text { individuais distintos. }\end{array}$ \\
\hline
\end{tabular}

Fonte: Adaptado de Bloom (1956) e Ferraz e Belhot (2010)

As fases de justaposição e comparação dessas informações possibilitaram a visualização e o detalhamento das áreas do crescimento cognitivo. Nesse sentido, elaboramos a Tabela 2.

A Tabela 2 foi constituída em cinco colunas: a primeira nomeia cada uma das áreas observadas ou seções dos livros; nas três seguintes, foram justapostos os percentuais calculados de cada livro, conforme os dados coletados; e na última coluna consta a média de cada linha. Cada linha corresponde à uma área do crescimento cognitivo de Bloom, onde se observou apenas o tema da Matemática Financeira, e na última linha temos as médias de cada coluna.

Como está tabulado na Tabela 2, na interseção da última linha com a última coluna, temos uma média geral, representada por $63 \%$. Esse indicador nos remete que, ao se observar todas as seções dos livros, temos uma aderência de $63 \%$ dos requisitos do crescimento cognitivo da 
Taxonomia de Bloom, nos materiais estudados.

Tabela 2: Percentual das áreas da Taxonomia de Bloom, por livro.

\begin{tabular}{|c|c|c|c|c|}
\hline Taxonomia de Bloom Livros & $\begin{array}{c}\text { Livro } \\
\text { A }\end{array}$ & $\begin{array}{l}\text { Livro } \\
\text { B }\end{array}$ & $\begin{array}{l}\text { Livro } \\
\text { D }\end{array}$ & $\begin{array}{l}\text { Média } \\
\text { Linha }\end{array}$ \\
\hline Lembrar & $40 \%$ & $80 \%$ & $40 \%$ & $53 \%$ \\
\hline Entender & $100 \%$ & $100 \%$ & $60 \%$ & $87 \%$ \\
\hline Aplicar & $80 \%$ & $100 \%$ & $60 \%$ & $80 \%$ \\
\hline Analisar & $60 \%$ & $80 \%$ & $60 \%$ & $67 \%$ \\
\hline Avaliar & $40 \%$ & $60 \%$ & $60 \%$ & $53 \%$ \\
\hline Criar & $0 \%$ & $60 \%$ & $60 \%$ & $40 \%$ \\
\hline Média & $53 \%$ & $80 \%$ & $57 \%$ & $63 \%$ \\
\hline
\end{tabular}

Fonte: Elaboração dos Autores

Nessa mesma visão, comparamos cada livro com essa média, e temos que o Livro B apresenta o melhor resultado, com $80 \%$ de adesão. Entretanto, os livros A e D ficaram na casa dos $50 \%$, sendo respectivamente, $53 \%$ e $57 \%$, não tendo alcançado a marca da média geral. Adiante, construiu-se um gráfico do tipo radar, para representar esses números, representado pelo Gráfico 2.

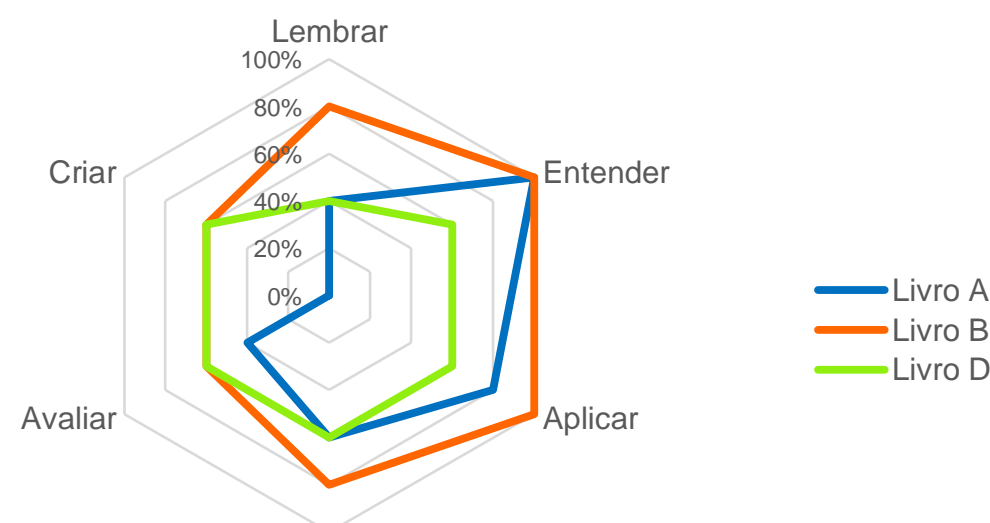

Analisar

Gráfico 2: Comparação da Taxonomia de Bloom nos livros didáticos (Elaboração dos Autores)

Esse tipo de gráfico faz relação entre os pontos obtidos e cria uma imagem geométrica, e por meio dela é possível perceber qual dos livros observados é mais aderente ao objetivo do estudo. Como abrangem seis parâmetros, espera-se que a figura geométrica seja um hexágono. 
Assim, percebe-se, pela representação do Gráfico 2, que o livro A preencheu uma pequena parte da área plotada; o livro B compreendeu uma grande área do gráfico; e o livro D ocupou apenas a área central da figura geométrica. Sob esse olhar, nota-se que a sequência com a melhor adesão à Taxonomia de Bloom, segundo os parâmetros, é assim representada: livro B, livro D e livro A.

\section{Considerações}

Por mais que seja discutida a importância de diversificar os mecanismos didáticos de ensino e aprendizagem, o livro didático pode ser considerado como o principal protagonista para a construção do conhecimento no espaço escolar. Nesse sentido, podemos elucidar que este recurso apoia a construção dos processos educativos.

Sobretudo, ressaltamos que o livro didático faz parte da prática escolar, articulado em diferentes enfoques educacionais e métodos de ensino, por ser uma solução de trabalho para 0 professor em sala de aula, auxiliando-o a escolher a matéria a ser trabalhada, estabelecer o tipo de abordagem, possibilitando a proposição de um trajeto próprio para a construção do saber.

Nesse contexto, o livro didático, atualmente, não aborda apenas conteúdos específicos das matérias escolares, mas sim o desenvolvimento do aluno como ser social ativo na sociedade, propondo e incentivando a convivência social. Assim, nota-se que vários desses livros trazem experiências e exemplos que podem ser aplicados na prática pelo aluno.

Consolidando o exposto acima, Frison et al. (2009) salientam que o livro didático contribui para a aprendizagem dos conteúdos, pois não se restringe apenas aos seus aspectos pedagógicos e às suas possíveis influências na aprendizagem e no desempenho dos estudantes. Além disso, exerce um papel político e cultural importante, porque produz valores da sociedade em sua relação com o conteúdo, história, ciência, interpretação dos fatos e o próprio processo de transmissão do conhecimento.

De modo geral, observou-se que, no que se refere à Educação Financeira, os livros didáticos de Matemática do Ensino Médio, listados no PNLD, conduzem à formação docente para aplicação dos conceitos e práticas voltadas para a Matemática Financeira e que acerca do tema da pesquisa, não foram encontrados elementos que vão além deste olhar.

Nesse aspecto, nota-se que a Educação Financeira é algo maior, que tem por propósito auxiliar os consumidores a administrar seus rendimentos, suas decisões de poupança e 
investimento, a consumir de forma consciente e ajudar a prevenir situações de fraude. Assim, muda o comportamento do cidadão frente às questões sociais em que se depara, tornando-o um ser ativo e crítico, permitindo refletir sobre suas práticas e ações no que se refere às finanças.

Porém, no contexto da formação docente, destaca-se que os livros didáticos do PNLD de 2017 estão aquém de oferecer conhecimento e formação para os professores, como se pode evidenciar pela média de $63 \%$. Nesse sentido, percebe-se uma necessidade de adequação desses materiais e fica evidente que esses materiais didáticos não conseguiram acompanhar as políticas públicas da educação no Brasil.

Assim, retomando o objetivo desta pesquisa, de analisar como os livros didáticos de Matemática do Ensino Médio, em relação à Educação Financeira, podem contribuir na formação do professor para que ele proporcione, aos seus alunos, a inserção no mundo do trabalho de forma ativa, crítica, criativa e responsável, perante aos desafios da contemporaneidade, é necessário um olhar atento às possibilidades interdisciplinares relativas à Educação Financeira. De forma geral, os livros abordam parte dessa formação, concentrando em cálculos, fórmulas e problemas envolvendo juros, prejuízos e empréstimos para o estudo da Matemática Financeira.

\section{Referências}

ANDERSON, Lorim W.; KRATHWOHL, David Reading. (Ed). A Taxonomy for lerarning, teaching, and assessing: a revision of Bloom's Taxonomy of Educational Objectives. New York: Person Education, 2001.

BATISTA, Amanda Penalva. Uma análise da relação professor e o livro didático. 2011. 64f. Trabalho de Conclusão de Curso (Pedagogia) - Departamento de Educação. Universidade do Estado da Bahia. Salvador, 2011.

BLOOM, Benjamim S. (Ed.). Taxonomy of educational objectives: the classification of educational goals. New York: David Mckay, 1956.

BRASIL. Instituto Brasileiro de Geografia e Estatística. Projeção da população do Brasil e das Unidades da Federação. Brasília: IBGE, 2020.

BRASIL. Instituto Nacional de Estudos e Pesquisas Educacionais Anísio Teixeira. Índice de Desenvolvimento da Educação Básica. 2018a.

BRASIL. Lei n 9.394, de 20 de dezembro de 1996. Estabelece as diretrizes e bases da educação nacional. Brasília: Diário Oficial da União, 23 dez. 1996.

BRASIL. Ministério da Educação. Secretaria de Educação Básica. Base Nacional Comum Curricular: Ensino Médio. Brasília: MEC/SEB, 2018b. 
BRASIL. Ministério da Educação. Secretaria de Educação Básica. Guia de livros didáticos do PNLD 2018: Ensino Médio, Matemática. Brasília: MEC/SEB, 2017.

CABALLERO, Angela; MANSO, Jesus; MATARRANZ; Maria; VALLE, Javier M. Investigación em Educación Comparada: pistas para investigadores noveles. Revista Latinoamericana de Educación Comparada, v. 9, n. 7, p. 39-56, 2016.

FERRAZ, Ana Paula do Carmo Marcheti; BELHOT, Renato Vairo. Taxonomia de Bloom: revisão teórica e apresentação das adequações do instrumento para definição de objetivos instrucionais. Gestão \& Produção, São Carlos, v. 17, n. 2, p. 421-431, 2010.

FRISON, Marli Dallagonl; VIANNA, Jaqueline; CHAVES, Jéssica Mello; BERNARDI, Fernanda Naimann. Livro didático como instrumento de apoio para construção de propostas de ensino de ciências naturais. In: ENCONTRO NACIONAL DE PESQUISA EM EDUCAÇÃO EM CIÊNCIAS, 7 , 2009, Florianópolis. Anais do 7 ENPEC. Florianópolis: ABRAPEC, 2009, p. 1-13.

KRATHWOHL, David Reading. A revision of Bloom's Taxonomy: an overview. Theory Into Practice, v. 4, n. 41, p. 212-218, ago. 2002.

LOURENÇO FILHO, Manoel Bergström. Educação Comparada. 3. ed. Brasília: INEP, 2004.

MARIM, Vlademir; FERREIRA, Wattson Estevão. Desafios do plano curricular para o Ensino Médio na formação cidadã. In: CIAVATTA, Maria. (Org.). A historicidade da questão curricular em Educação Profissional e Tecnológica. Jundiaí: Paco Editorial, 2015, p. 119-146.

MARIM, Vlademir; FERREIRA, Wattson Estevão; BERNADES, Maria Beatriz Junqueira; FRANCO, Karla Oliveira. Um panorama sobre as propostas curriculares para o Estado de Minas Gerais. In: MARIM, Vlademir; FERREIRA, Wattson Estevão. (Org.). Desafios do plano curricular para 0 Ensino Médio na formação cidadã. Jundiaí: Paco Editorial, 2015, p. 17-43.

MARIM, Vlademir; SOUZA, Anália Barreto. Os livros didáticos de Matemática: concepção do professor do Ensino Médio nas Escolas Públicas. Revista de Educação, Ciências e Matemática, Duque de Caxias, v. 5, n. 2, p. 111-124, maio 2015.

OLIVEIRA, João Batista Araújo; GUIMARÃES, Sonia Dantas Pinto; BOMÉNY, Helena Maria Bousquet. A política do livro didático. Campinas: EdUnicamp, 1984.

PAULINO, Suzana Ferreira. Livro tradicional x livro eletrônico: a revolução do livro ou uma ruptura definitiva? Hipertextus, Recife, v. 3, n. 2, p. 1-13, jun. 2009.

PESCUMA, Derma; CASTILHO, Antonio Paulo Ferreira de. Projeto de pesquisa: o que é? Como fazer? 8. ed. São Paulo: Olho D'Água, 2013.

PRODANOV, Cleber Cristiano; FREITAS, Ernani Cesar de. Metodologia do Trabalho Científico: métodos e técnicas de pesquisa e do trabalho acadêmico. 2. ed. Novo Hamburgo: Universidade Feevale, 2013. 